\title{
Revision of the Italian Magnetic Database for the Albegna basin (South Tuscany, Italy)
}

\author{
Guido Dominici ${ }^{\star}$, Antonio Meloni
}

Istituto Nazionale di Geofisica e Vulcanologia, Sezione Roma 2, Rome, Italy

\author{
Article history \\ Received March 6, 2014; accepted June 26, 2014. \\ Subject classification: \\ Geomagnetism, Magnetic survey, Reference field, Secular variation, Magnetic cartography.
}

\begin{abstract}
A comparison between ground level total magnetic field intensity anomaly map (F) of Italy and the total intensity aeromagnetic map by ENI/AGIP, had shown that an anomaly pattern for the Albegna basin (South Tuscany), quite evident from ground measurements, doesn't show in the aeromagnetic map. Ligurian units, made of ophiolite blocks (metagabbros, basalts, serpentinites), intrusives and subordinate volcanic products, all able to trigger a strong magnetic signal, could not be excluded in the area, and for this reason the magnetic anomaly estimated by ground level measurements was not considered unreasonable. In this paper the result of a magnetic survey finalized to verify the authentic existence of such a large magnetic total intensity anomaly in the Albegna basin, is reported. On the basis of the new result, the suspected ground level total intensity anomaly in the Albegna basin, was demonstrated to be non-existent and then the Italian Magnetic Database corrected accordingly. Measurements and procedures that brought to the magnetic elements elaboration and new anomaly maps for Albegna basin, are shown here.
\end{abstract}

\section{Ground level magnetic maps and the sea level magnetic anomaly map of Italy}

Magnetic field measurements are undertaken in different ways and for different reasons. Observatories monitor time variations of the field, while measurements carried out on land and sea by ships, helicopters, planes, and also onboard satellites at low orbital altitudes, provide information concerning the spatial structure of the field and then give information on the main Earth's magnetic field and on that of crustal origin. In particular, for crustal magnetism studies, ground measurements are widely used for their immediate proximity to the magnetic sources. Information on Earth's magnetism can be found, for example, in Campbell [2003], Lanza and Meloni [2006], Encyclopedia of Geomagnetism and Paleomagnetism [2007].

In many nations, ground magnetic measurements are organized in networks of survey points. The socalled first order networks are devoted mainly to secu- lar variation monitoring, while second order networks, with higher spatial detail, are dedicated to geomagnetic elements map compilation and to crustal magnetism studies. As shown in Figure 1, the first order Italian magnetic network has an average stations spacing of about $100 \mathrm{~km}$, while the second order network has an average spacing of about $5-10 \mathrm{~km}$.

Every five years, for their institutional roles, INGV (Istituto Nazionale di Geofisica e Vulcanologia) and IGM (Istituto Geografico Militare) carry out measurements (total intensity $F$, horizontal component $H$, vertical component $Z$, declination $D$ and inclination $I$ ) over the about 120 repeat stations of the first order magnetic network (Figure 1). The aim of this periodic effort is to replicate magnetic measurements at repeat stations in order to monitor geomagnetic field secular variation and to compute updated coefficients of regional models for representing the main geomagnetic patterns over Italy, at the various epochs.

In Italy ground level magnetic measurements on the second order network were performed in an organized national effort only once between 1977 and 1981, within the framework of the Progetto Finalizzato Geodinamica of the Consiglio Nazionale delle Ricerche (PFG-CNR). All the work was coordinated by the then ING (Istituto Nazionale di Geofisica). At that time a database of 2552 magnetic data (total intensity $F$, horizontal component $H$, vertical component $Z$ ) was assembled with the objective to produce magnetic field maps of Italy for intensive elements and to successively compile a magnetic crustal field anomaly map for Italy [Molina et al. 1986].

Magnetic anomaly maps are produced starting from field measurements, after the Earth's core field and magnetic time variations, are removed. The removal of the core main field is generally undertaken by subtraction of IGRF (International Geomagnetic Reference Field; Finlay et al. [2010]) or by the removal of 


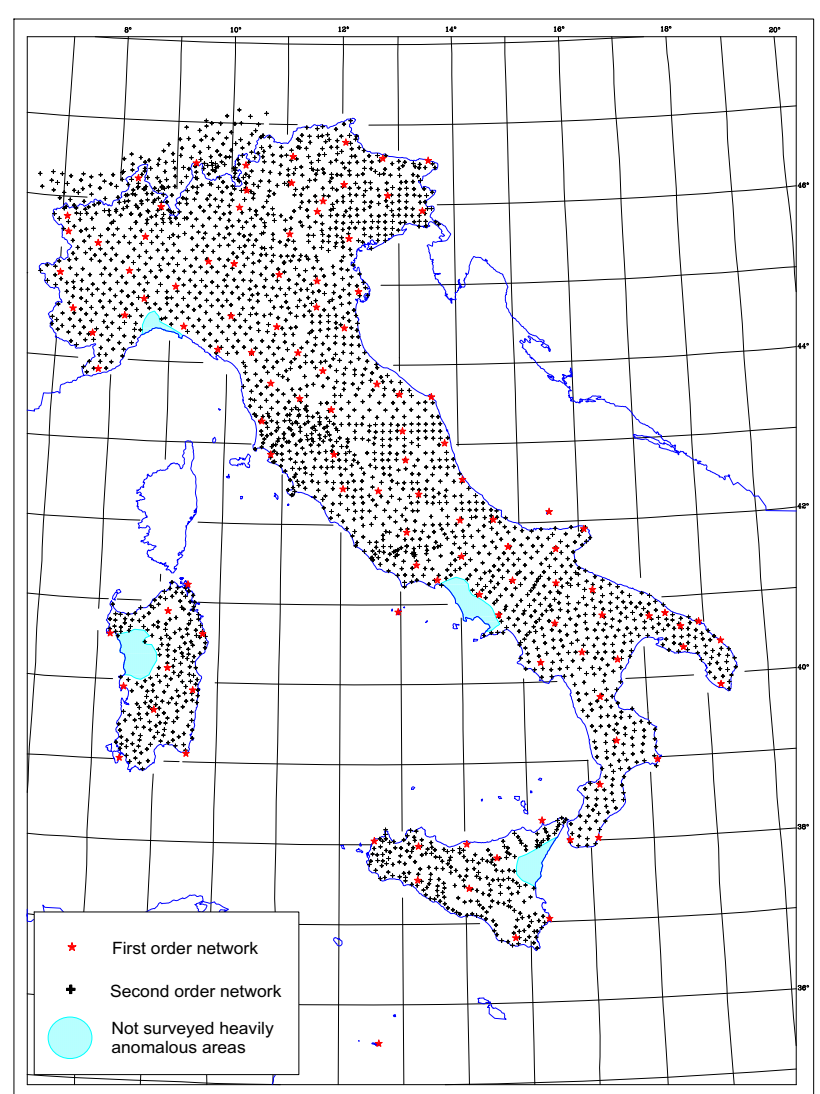

Figure 1. Italian magnetic measurements network. Red stars refer to first order network (repeat stations) while black crosses refer to the second order network points, as undertaken by PFG-CNR for elements $F, H$ and $Z$. All second order network data points were measured between 1977-1981, while only first order network points are repeated every five years for secular variation monitoring.

an equivalent regional magnetic field that can be derived directly from measured data. Removal of time variations of Earth's magnetic field is done by using a Magnetic Observatory time measurements. In our case all field measurements are reduced to nighttime level (generally $02.00 \mathrm{UT}$ ) and corrected for diurnal and possible perturbations in the field. Magnetic field maps of Italy for intensive elements $(F, H$ and $Z$ ), from second order network data, were published for the land areas [Molina et al. 1985] and also a total field anomaly magnetic map was produced and published, initially for the land area only, excluding the surrounding seas [Molina et al. 1994].

One important result of the five year surveys on the first order network, is to provide an analytical formula able to represent, at large, the Earth's core magnetic field over a certain area, this is the so-called regional magnetic field model. Regional fields can be formulated as a second order degree polynomial expression of the form $E(\phi, \lambda)=a_{0}^{\prime}+a_{1} \phi+a_{2} \lambda+a_{3} \phi^{2}+$ $a_{4} \lambda^{2}+a_{5} \phi \lambda$ where $E$ is the generic geomagnetic element, $\lambda$ the longitude, $\phi$ the latitude (both expressed in degrees or minutes of arc), $a_{0}^{\prime}$ is the base level (in nT) for each element, $a_{n(n=1.5)}$ are the coefficients, expressed in $\mathrm{nT} /$ degree or $\mathrm{nT} /$ minutes of arc in longitude and latitude. Even if regional field models can include some contribution of deep crustal origin, superimposed to the core field, it has been shown that at the spatial scale of Italy they are in a good fit to IGRF [Finlay et al. 2010] and effectively represent the core field (see for example, De Santis et al. [1997]). In Italy the regional polynomial expression called ItGRF (Italian Geomagnetic Reference Field) is regularly updated by using the five years repeat station measurements: this model avoids the boundary effects that are commonly present in the regional fields and makes use of the secular variation as determined by Observatory measurements (for details, see De Santis et al. [2003]).

Once regional models are computed at five year intervals, they are used to update all measurements of the Italian area, like for example second order network data points. Every five years the national maps of magnetic elements at the specific epoch are then redrawn and the magnetic database is updated. For the various procedures on this point see Dominici et al. [2007], and the last compilation for year 2010.0 in Dominici et al. [2012].

Between 1965-1972, 28,833 offshore total field intensity data were acquired by oceanographic ships by the Osservatorio Geofisico Sperimentale (OGS) in the seas surrounding Italy [Morelli et al. 1969, Morelli 1970a, 1970b]. At the end of the 90s of last century, onshore and offshore total field data were merged in order to obtain a single, large total field data set. This data set was then reprocessed and all data were reduced to the common epoch 1979.0, using the ItGRF as main regional reference field. All data (2552 onshore and 28,833 offshore) elaborated by INGV, constitute the Italian Magnetic Database.

Finally, data of the Italian database wase integrated for the compilation of a sea level shaded relief magnetic anomaly map of total intensity magnetic field for Italy and the surrounding seas, for the geomagnetic epoch 1979.0 [Chiappini et al. 2000]. The published map was considered the final product of a long time effort, allowing an unprecedented view of magnetic anomalies in Italy and showing their relations to the major tectonic elements in their regional setting, confirming a good correlation between known structural geology and magnetic anomalies.

\section{Aeromagnetic anomaly map of Italy}

For what concerns aeromagnetic investigations, the Italian national Oil Company AGIP (Azienda Generale Italiana Petroli, now part of ENI, Ente Nazionale Idrocarburi) commissioned an aeromagnetic survey of Italy to a private company in the early 70 s of last century. AGIP collected all total field magnetic data at var- 

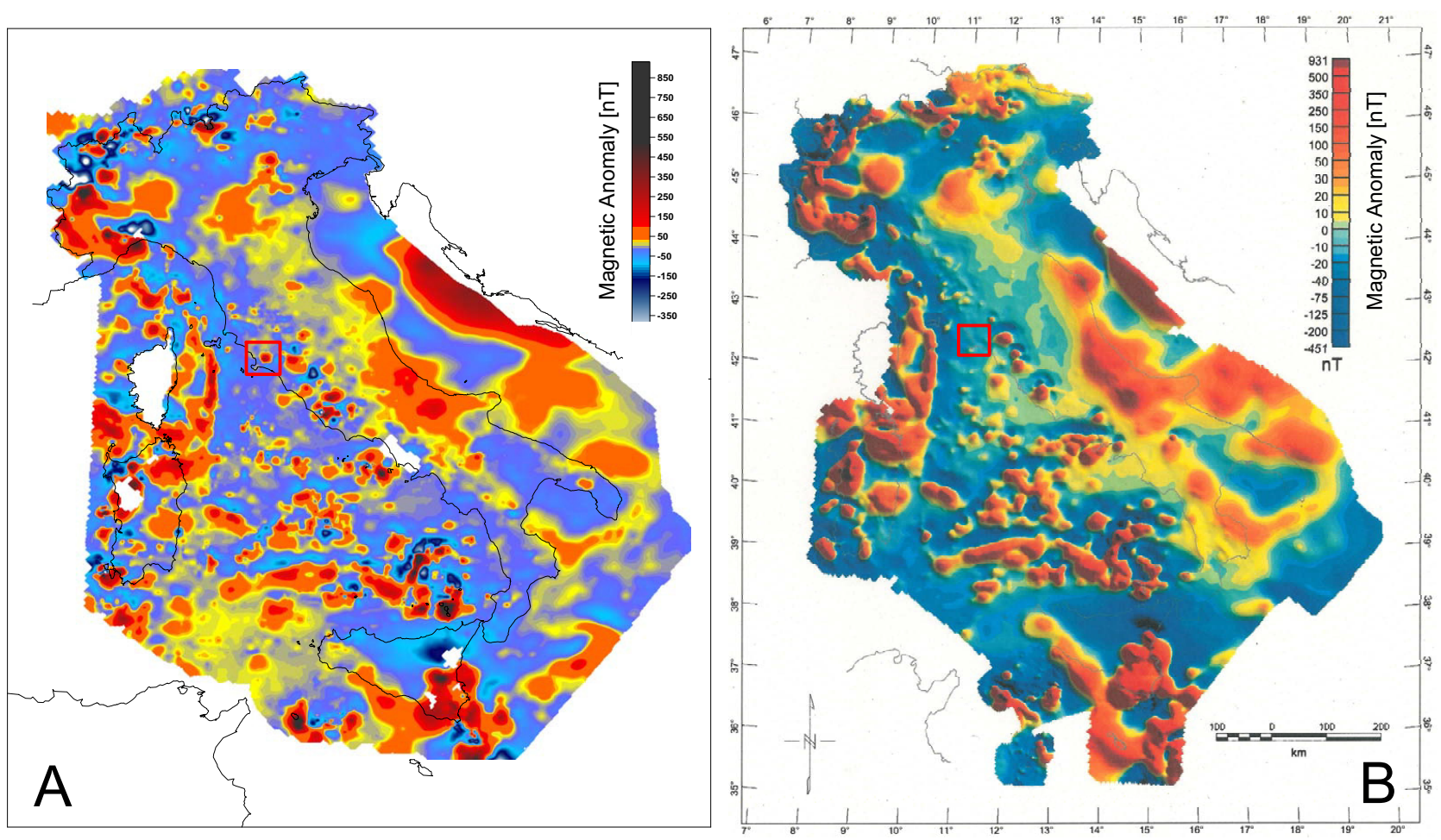

Figure 2. Total intensity magnetic anomaly maps: A) ground level from Italian database; B) aeromagnetic from AGIP/ENI database. In both maps, the red rectangles show the area referred to in this paper.

ious altitudes, and drew a first aeromagnetic anomaly map for the Italian territory in 1981 and a later contour version superimposed to regional geological features in 1994 [AGIP 1981, Cassano et al. 1986, Servizio Geologico Nazionale 1994].

An inspection of the two maps, the one produced by INGV at ground level, and the one produced by AGIP, has shown differences that could not be attributed to measurement problems. This was noticeable especially in the long wavelength magnetic anomaly features. It was realized that the discrepancy could be attributed to an incorrect removal of the reference field from measurements in the AGIP aeromagnetic compilation map; in fact, neither the IGRF or other regional magnetic models were used for reference. Only in 2005, after a revised version of the aeromagnetic map of Italy and surrounding seas was undertaken (also including the addition of some new surveys), AGIP company allowed a re-processing of all the aeromagnetic data set. The result of this work was a new map that used IGRF as main reference field [Caratori Tontini et al. 2004]. The detailed reprocessing of aeromagnetic data at the national scale, the inclusion of the new data, the subtraction of an appropriate reference level, are the main reasons for the tangible enhancement of the anomaly definition emerging from this new aeromagnetic anomaly compilation.

Finally the two anomaly maps, ground level and aeromagnetic, could be fruitfully used for magnetic crustal studies. The two maps are in fact comparable, provided that INGV map is referred to the sea level and the AGIP-ENI map to an average elevation of $2500 \mathrm{~m}$ and, consequently, the resulting anomalies are enhanced or flatted in the two maps.

Figure 2 shows the maps from Italian database (panel A) and ENI/ AGIP database (panel B). One of the local striking features that comes to the eye in the comparison of the two maps at the local scale, is the case of the Albegna basin (South Tuscany), that is the area delimited by the red square. In fact, the two maps display a different anomaly structure in this area. In detail, a strong magnetic anomaly circularly shaped that can be seen in the ground level map (panel A), does not show in the aeromagnetic map (panel B).

\section{Albegna basin: geological characteristics and mag- netic implications}

The study area of interest for this paper (Figure 3) is located in the Neogene Albegna basin, a region characterized by a complex tectonic and sedimentary evolution. This area is delimited to the north by the volcanic complex of the Mount Amiata and to the east by the volcanic complex of the Vulsini Mountains. In the compressive phase (ended in the Early Miocene), the crust thickening resulted in an emplacement of tectonic units originating by different paleogeographic domains. Various authors [Bettelli 1980, Bonazzi et al. 1992, Bonciani et al. 2005] worked out a dynamic preand syn-collisional tectonic model for the area and a post-collisional extension event framework. 


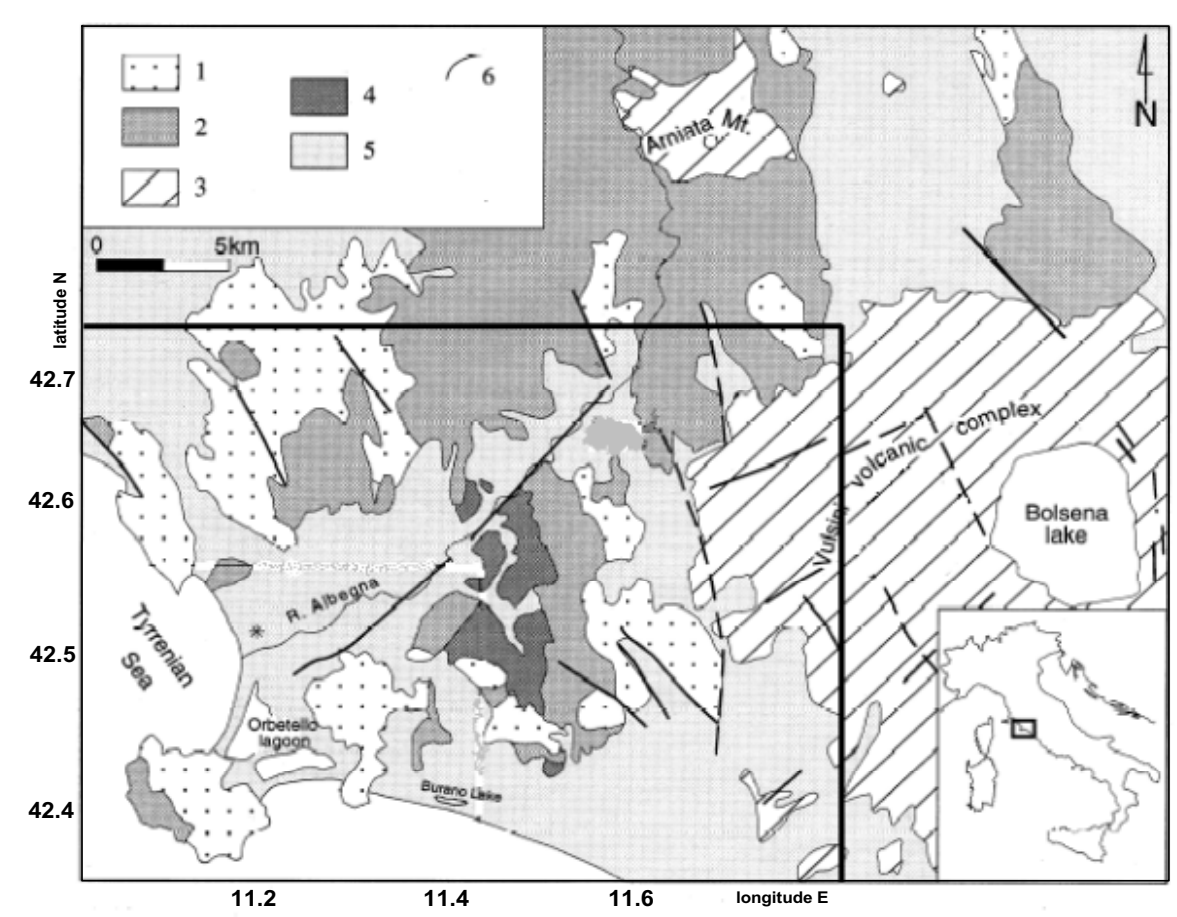

Figure 3. Geological sketch map of Albegna Basin. Legend: $1=$ Tuscan units; $2=$ Ligurian units; $3=$ Mt. Amiata and Vulsini volcanic units; 4=Miocene clastic deposits; $5=$ =Pliocene-Holocene sedimentary units; $6=$ normal faults; the rectangle on the map refers to the area referred in this paper.

From the bottom to the top, the Nappe (Nappe is a large sheetlike rock that has been moved from original position for tectonic movements) superposition is represented by:

- the metamorphic units of the Tuscan basement that crop out in the south-east margin of the area with the "Verrucano Formation";

- the Tuscan Nappe Unit, a sedimentary succession, that ranges from the evaporites of "Anidriti di Burano Formation" to the sandstone and siltstone of "Macigno Formation", with wide outcrop in this area;

- the Ligurian Unit, a tectonic unit derived from external oceanic domain (the "Canetolo Formation", the "Pietraforte Formation") up to the internal oceanic Ligurian Domain of "Ofioliti Formation".

Then, in the extensional events, the sedimentation is represented by continental-lacustrine deposits controlled by a system of normal faults NNW-SSE with crustal thinning and after, in the Lower Pliocene, by a transgressive sequence where an unconformity sedimentation of shallow-marine deposits controlled by a different system SW-NE takes place; the sedimentary evolution ended with Pleistocenic sequences.

The presence, in the Ligurian units, of ophiolite blocks (metagabbros, basalts, serpentinites) which trigger a strong magnetic signal, is a possible source of magnetic crustal anomaly. Ophiolites are not detected in the study area (they are certainly present only at north) but the hypothetical occurrence of ophiolite blocks below the sedimentary successions which filled the Albegna basin, could not be excluded. Another important magnetic inference is given by the magmatic activity (7.0-4.0 Ma) related to the extensional process [Carmignani et al. 1994, Jolivet et al. 1998, Acocella et al. 2002], mainly through anatectic intrusives and subordinate volcanic products, as in the near Tuscan Magmatic Province of Mount Amiata, or the younger (1.7 Ma-present) potassium alkaline volcanism of the Roman Province, as in the near volcanic complex of the Vulsini Mountains. Moreover, a possible uplift of a magmatic batholith can also be a cause of magnetic anomaly, although not supported by other data.

For all reasons above reported the magnetic anomaly found in the ground level map in the Albegna basin, was considered reasonable and only after the final compilation of the new aeromagnetic map, the area was taken in consideration for deeper investigation.

\section{Magnetic survey and elaboration}

Figure 4 shows the second order network onshore data (red crosses) and the contour values of the total field magnetic anomaly for the region of interest. The mean distance between the stations is of about $9 \mathrm{~km}$. The definitive answer to the question whether the anomaly under investigation was real or not could come only from a new set of measurements. For this reason a new dedicated magnetic survey was performed in area: in Figure 4 the 19 stations of the new survey are marked in blue points.

The distribution of the new measurement points 


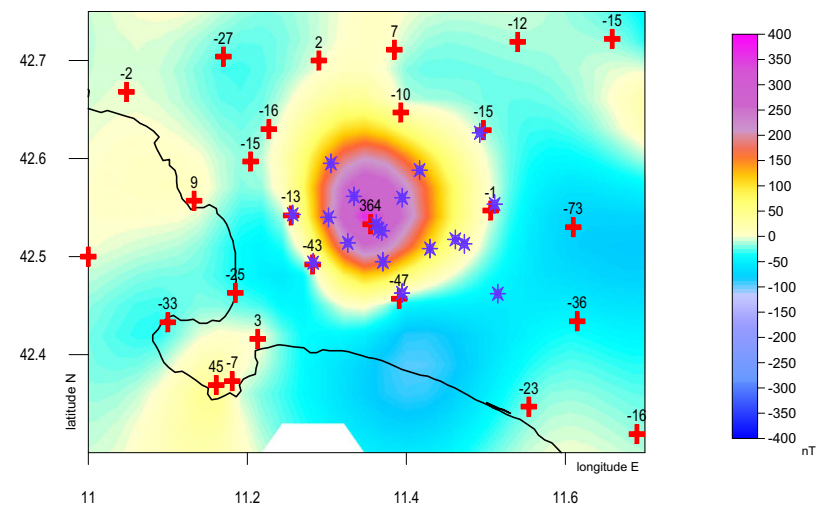

Figure 4. Total intensity anomaly map over Albegna Basin: crosses show the onshore stations from Italian database with the corresponding values of anomaly, and blue stars indicate the new measurements.

was focused to obtain a concentric geometry and the doubling of the density of stations around the anomaly centre. Some stations of the new survey are very near to the stations of the old network, i.e. stations number $1,13,16,17,18,19$. At these stations the total field $F$ was measured with an Overhauser magnetometer, and also the magnetic inclination $I$ with a DIM, Declination Inclination Magnetometer. At the other stations only the total field $F$ was measured.

All new measurements were reduced to a common day-time, at $02_{U T}$ hour (considered as the magnetic quite time level) and, using L'Aquila Observatory data $(A q)$, to a mean epoch. The general procedure requires that the value of element $E$ (i.e., $F, H$ or $Z$ ) at station $s$, reduced at $02_{U T}$ of day $d$ (for this survey the day is September 3rd, 2007), is calculated following the formula:

$$
E_{s}\left(02_{U T}\right)_{d}=E_{A q}\left(02_{U T}\right)_{d}+\left\lfloor E_{s}(t)_{d}-E_{s}(t)_{d}\right\rfloor
$$

where $E_{s}\left(02_{U T}\right)_{d}$ is the value of $E$ at station $s$ reduced at time $02_{U T}$ of day of measure $d, E_{A q}\left(02_{U T}\right)_{d}$ is the value of $E$ at Observatory at time $02_{U T}$ of day of measure $d$, $E_{s}(t)_{d}$ is the value of element $E$ observed at station $s$ at time $t$ at that day $d, E_{A q}(t)_{d}$ is the value of element $E$ at Observatory at time $t$ at that day $d$. In Table 1 the geographic coordinates of the stations with the values at the ground level of $E_{S}\left(02_{U T}\right)_{09 / 03 / 2007}$, where $E$ is the magnetic element, are reported.

The Element $E$ at station $s$ computed at epoch 2005.0 (January 1st, 2005) is obtained according to

$$
E_{s}(2005.0)=E_{A q}(2005.0)+\left\lfloor E_{s}\left(02_{U T}\right)_{d}-E_{A q}\left(02_{U T}\right)_{d}\right\rfloor,
$$

where $E_{s}(2005.0)$ is the value of $E$ at station $s$ reduced at

\begin{tabular}{|c|c|c|c|c|c|c|}
\hline Station & Latitude & Longitude & Elevation & $F_{s}\left(02_{U T}\right)_{09 / 03 / 2007}$ & $H_{s}\left(02_{U T}\right)_{09 / 03 / 2007}$ & $Z_{s}\left(02_{U T}\right)_{09 / 03 / 2007}$ \\
\hline 1 & 42.53350 & 11.36221 & 128 & 46251.4 & & \\
\hline 2 & 42.52823 & 11.36488 & 122 & 46262.9 & & \\
\hline 3 & 42.52625 & 11.36918 & 105 & 46258.1 & 24040.5 & 39520.4 \\
\hline 4 & 42.56002 & 11.39479 & 105 & 46266.5 & & \\
\hline 5 & 42.56148 & 11.33409 & 64 & 46260.4 & & \\
\hline 6 & 42.50813 & 11.42970 & 109 & 46260.8 & & \\
\hline 7 & 42.46215 & 11.51502 & 190 & 46291.3 & & \\
\hline 8 & 42.51749 & 11.46162 & 88 & 46332.7 & & \\
\hline 9 & 42.51301 & 11.47297 & 110 & 46279.3 & & \\
\hline 10 & 42.54005 & 11.30206 & 12 & 46261.6 & & \\
\hline 11 & 42.51400 & 11.32638 & 16 & 46236.0 & & \\
\hline 12 & 42.49473 & 11.37053 & 34 & 46301.2 & & \\
\hline 13 & 42.46282 & 11.39454 & 45 & 46199.0 & 24026.6 & 39459.7 \\
\hline 14 & 42.58813 & 11.41664 & 89 & 46281.5 & & \\
\hline 15 & 42.59515 & 11.30521 & 66 & 46267.8 & & \\
\hline 16 & 42.54303 & 11.25712 & 21 & 46254.3 & 24002.2 & 39539.3 \\
\hline 17 & 42.49373 & 11.28276 & 71 & 46222.8 & 24021.3 & 39490.8 \\
\hline 18 & 42.62627 & 11.49241 & 224 & 46288.9 & 23946.9 & 39613.2 \\
\hline 19 & 42.55345 & 11.51112 & 235 & 46265.7 & 23986.4 & 39562.2 \\
\hline
\end{tabular}
epoch 2005.0, $E_{A q}(2005.0)$ is the average value of $E$ at

Table 1. Coordinates of stations with the values of magnetic elements at $02_{U T}$ hours of day September $3 \mathrm{rd}, 2007$. 


\begin{tabular}{lrrrrrr}
\hline $\mathrm{F}(\mathrm{nT})=46063.1+5.72335$ & $\varphi+1.22044$ & $\lambda-0.00184$ & $\varphi^{2}-0.00003$ & $\lambda^{2}-0.00047 \varphi \lambda$ & 2005.0 \\
$\mathrm{~F}(\mathrm{nT})=45388.4+5.709$ & $\varphi+1.111$ & $\lambda-0.00153$ & $\varphi^{2}+0.00049$ & $\lambda^{2}-0.00068 \varphi \lambda$ & 1979.0 \\
\hline $\mathrm{H}(\mathrm{nT})=24283.9-9.38524$ & -0.09122 & $\lambda+0.00009$ & $\varphi^{2}-0.00008$ & $\lambda^{2}+0.00002 \varphi \lambda$ & 2005.0 \\
\hline $\mathrm{H}(\mathrm{nT})=24104.2-9.043$ & $\varphi$ & +0.110 & $\lambda+0.00036$ & $\varphi^{2}+0.00004$ & $\lambda^{2}-0.00042 \varphi \lambda$ & 1979.0 \\
\hline $\mathrm{Z}(\mathrm{nT})=39133.1+12.68257 \varphi+1.60346$ & $\lambda-0.00493$ & $\varphi^{2}-0.00016$ & $\lambda^{2}-0.00122 \varphi \lambda$ & 2005.0 \\
$\mathrm{Z}(\mathrm{nT})=38451.7+12.467$ & $\varphi$ & +1.259 & $\lambda-0.00444 \varphi^{2}+0.00060$ & $\lambda^{2}-0.00069 \varphi \lambda$ & 1979.0
\end{tabular}

Table 2. Coefficients of the Italian Geomagnetic Reference Field (ItGRF) for the epochs indicated at the end of each row, for the magnetic elements $F, H, Z$. Latitude $\varphi$ and longitude $\lambda$ are referred to $42^{\circ} \mathrm{N}$ and $12^{\circ} \mathrm{E}$, respectively, with values expressed in degrees. $F, H, Z$ are in nT.

L'Aquila Observatory at epoch 2005.0, $E_{A q}\left(02_{U T}\right)_{d}$ is the value of $E$ at L'Aquila Observatory at time $02_{U T}$ of the day of measure $d, E_{s}\left(02_{U T}\right)_{d}$ is the value of $E$ at station $s$ at time $02_{U T}$.

Considering that each station $F$ value had its own elevation above sea level, a reduction to the sea level for all stations data has been made considering only the Earth's centered dipole contribution, according to the equation $\Delta E=3 E h / R$, where $E$ is the generic geomagnetic element, $h$ is the station elevation a.s.l., $R$ is the average Earth radius.

Finally, in order to make this survey exploitable for a comparison with the published anomaly maps, all data were reduced at the epoch 1979.0, using the secular variation computed by the regional main reference field ItGRF. In Table 2 the expressions with the coeffi-

\begin{tabular}{|c|c|c|c|c|c|c|c|c|c|c|c|c|}
\hline 节 & 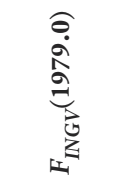 & 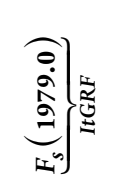 & 密 & 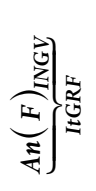 & 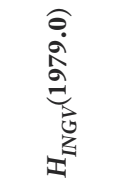 & 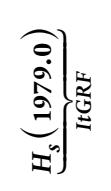 & 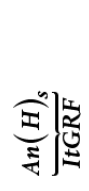 & $\underbrace{\stackrel{0}{3}}_{\frac{3}{4}}$ & 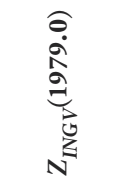 & $\left.\begin{array}{c}\hat{\theta} \\
\hat{0} \\
\hat{\Xi} \\
N\end{array}\right\}$ & 恿| & 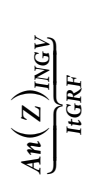 \\
\hline 1 & & 45490.8 & -21 & & & & & & & & & \\
\hline 2 & & 45502.3 & -8 & & & & & & & & & \\
\hline 3 & 45891.0 & 45497.5 & -12 & 381 & 24538.0 & 23863.2 & 8 & -317 & 38780.0 & 38747.9 & -9 & 23 \\
\hline 4 & & 45505.8 & -17 & & & & & & & & & \\
\hline 5 & & 45499.8 & -20 & & & & & & & & & \\
\hline 6 & & 45500.1 & -8 & & & & & & & & & \\
\hline 7 & & 45530.5 & 34 & & & & & & & & & \\
\hline 8 & & 45571.9 & 58 & & & & & & & & & \\
\hline 9 & & 45518.5 & 6 & & & & & & & & & \\
\hline 10 & & 45501.1 & -11 & & & & & & & & & \\
\hline 11 & & 45475.5 & -29 & & & & & & & & & \\
\hline 12 & & 45540.6 & 40 & & & & & & & & & \\
\hline 13 & 45457.0 & 45438.4 & -53 & -34 & 23906.0 & 23848.7 & -42 & 16 & 38663.0 & 38687.3 & -26 & -50 \\
\hline 14 & & 45520.7 & -14 & & & & & & & & & \\
\hline 15 & & 45507.3 & -22 & & & & & & & & & \\
\hline 16 & 45511.0 & 45493.9 & -16 & 2 & 23883.0 & 23823.1 & -23 & 37 & 38741.0 & 38768.3 & 6 & -21 \\
\hline 17 & 45465.0 & 45462.5 & -31 & -29 & 23902.0 & 23841.9 & -31 & 29 & 38675.0 & 38719.8 & -7 & -52 \\
\hline 18 & 45549.0 & 45527.9 & -21 & 0 & 23796.0 & 23773.5 & -27 & -4 & 38839.0 & 38838.3 & 1 & 2 \\
\hline 19 & 45537.0 & 45504.7 & -21 & 11 & 23863.0 & 23812.1 & -28 & 23 & 38784.0 & 38787.6 & 3 & -1 \\
\hline
\end{tabular}

Table 3. Values of magnetic element at 1979.0: $E_{I N G V}(1979.0)=$ values of element $E$ at 1979.0 from Italian database; ${ }^{\circ}=$ values of element $E$ on station $s$ reduced at 1979.0 with the ItGRF; ${ }^{\circ}=$ values of anomaly of the element $E$ on station $s$ respect ItGRF; ${ }^{\circ \circ}=$ values of anomaly of the element $E$ on Italian database with respect to ItGRF.

${ }^{\circ} \underbrace{E_{s}(1979.0)}_{\text {Itgrf }} ;{ }^{\circ} \underbrace{A n(E)_{s}}_{\text {ItGRF }} ;{ }^{\circ \circ} \underbrace{A n(E)_{I N G V}}_{\text {ItGRF }}$. 
cients of the reference field ItGRF are listed. ItGRF 1979.0 epoch values are calculated by linear interpolation between neighboring sets 1975.0 and 1980.0.

The value of the generic element $E$ at the epoch 1979.0 is deduced by

$E_{s}(1979.0)=E_{s}(2005.0)-\left\lfloor E_{I t G R F}(2005.0)-E_{I t G R F}(1979.0)\right\rfloor$

where $E_{I t G R F}($ epoch) is the value of element $E$ calculated with the expressions of Table 2 at the two epochs, and $\left\lfloor E_{I t G R F}(2005.0)-E_{I t G R F}(1979.0)\right\rfloor$ represents the value of secular variation between the two epochs. In Table 3 all values of measurements reduced at the epoch 1979.0 with the secular variation calculated by ItGRF and the anomalies values with respect the ItGRF, both for this survey and for Italian database are reported.

\section{Conclusions}

In this paper we have considered two total magnetic anomaly field maps compiled for Italy in the last years. The first is the sea level shaded relief magnetic anomaly map of total intensity of the Earth's magnetic field for Italy and the surrounding seas, for the geomagnetic epoch 1979.0 [Chiappini et al. 2000]. The second is the aeromagnetic map [Caratori Tontini et al.

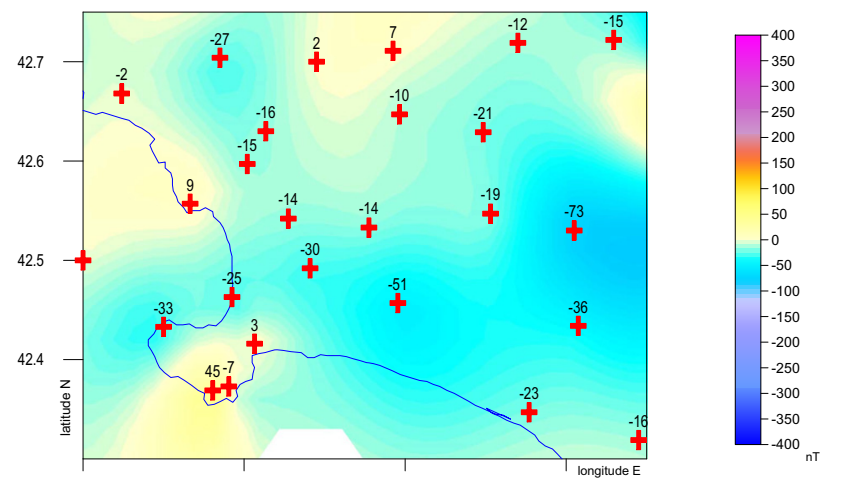

Figure 5. New total intensity anomaly map over Albegna Basin: crosses indicate the onshore stations by Italian database now corrected.

2004] compilation obtained after a revision of an older version of the aeromagnetic map of Italy, and surrounding seas originally undertaken by AGIP, and referred to the same epoch.

One of the striking features that emerged from the comparison of the two maps, was a discrepancy in the area of the Albegna basin (South Tuscany). In Figure 2 the dissimilar anomaly structure in the area is delimited by red squares. A strong magnetic anomaly, circularly shaped, can be clearly seen in the ground level map but not in the aeromagnetic map.
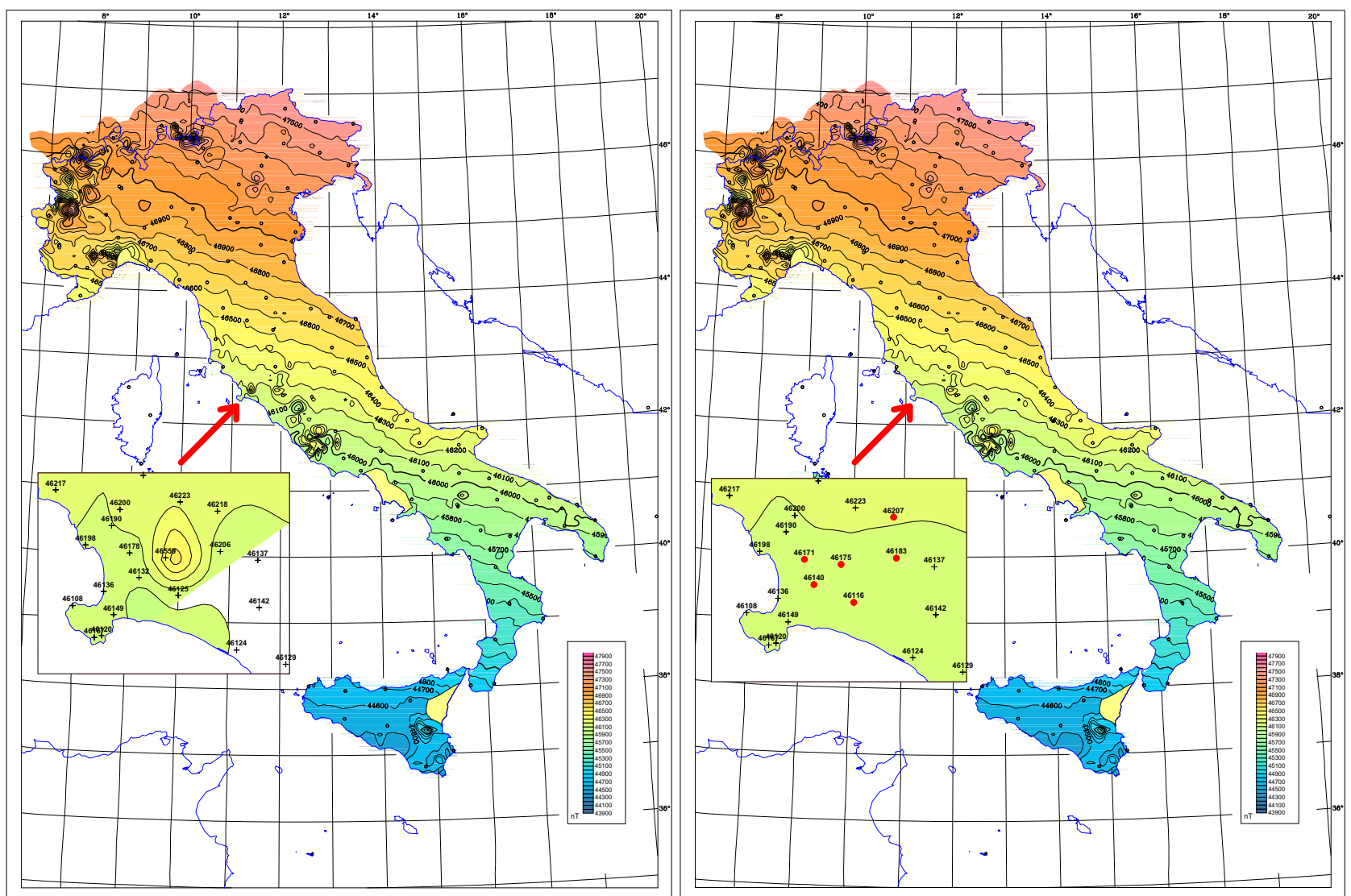

Figure 6. Two maps for comparison. Left: map of total field $F$ at 2005.0 by Italian database with the enlargement of Albegna basin and values. Right: map of $F$ at 2005.0 by Italian database corrected after new data from survey described in this paper were included (red points in the enlargement). 
A magnetic survey made on purpose in 2007, with the data reduction to 1979.0 for a common reference epoch with the two above mentioned maps, was undertaken. By means of an independent new data set, a new evaluation of the situation is now possible. The new survey shows clearly that that there is no inconsistency between the two sets of ground level data except for the large anomaly value reported in the Chiappini et al. [2000] map, and not at all present in the new survey results. This holds true not only for total field $F$ but also for horizontal intensity $H$ (not shown here), computed after also new inclination data $I$ were used in this new elaboration. With this last consideration we assume that the old ground level measurements set included a wrong measurement value for $F$. After this revision of the total field data set, the incorrect station value in the Italian database was corrected and, as reported in Figures 5 and 6 the total intensity anomaly map for this area and the geomagnetic field map were redrawn.

In the Albegna area possible sources of magnetic crustal anomaly are actually present, Ligurian units of ophiolite blocks (metagabbros, basalts, serpentinites), subordinate volcanic products, as in the near Tuscan Magmatic Province of Mount Amiata, or the younger (1.7 Ma-actual) potassium alkaline volcanism of Roman Province, as in the near volcanic complex of the Vulsini Mountains. For this reason the magnetic anomaly detected in the Albegna area was initially considered feasible. However, after the new magnetic survey and following data elaboration, as shown in this paper, we can conclude that no strong magnetic anomalies are present in the area.

Aknowledgements. We would like to express our sincere gratitude to M. Miconi for his help in the survey work.

\section{References}

Acocella, V., V. Pascucci and G. Dominici (2000). Basin deformation due to the laccolith emplacement at Radicofani (southern Tuscany, Italy), B. Soc. Geol. Ital., Special issue, 1, 749-756.

Agip SpA (1981). Italia, Carta magnetica: anomalie del campo magnetico residuo, scale 1:500,000, San Donato Milanese, Italy.

Bettelli, G. (1980). Le unità tettoniche del complesso ligure nell'area fra il F. Albegna e il F. Fiora (Toscana meridionale), Mem. Soc. Geol. Ital., 21, 157-161.

Bonazzi, U., P. Fazzini and G. Gasperi (1992). Note alla carta geologica del fiume Albegna, B. Soc. Geol. Ital., 111, 341-354.

Bonciani, F., I. Callegari, P. Conti, G. Cornamusini and L. Carmignani (2005). Neogene post-collisional evolution of the internal Northern Apennines: insights from the upper Fiora and Albegna valleys (Mt. Amiata geothermal area, southern Tuscany), B. Soc. Geol. Ital., Special issue, 3, 103-118.

Campbell, W. (2003). Introduction to Geomagnetic Fields, Cambridge University Press, 352 pp.

Caratori Tontini, F., P. Stefanelli, I. Giori, O. Faggioni and C. Carmisciano (2004). The revised aeromagnetic anomaly map of Italy, Annals of Geophysics, 47 (5), 1547-1555.

Carmignani, L., F.A. Decandia, P.L. Fantozzi, A. Lazzarotto, D. Liotta and M. Meccheri (1994). Tertiary extensional tectonics in Tuscany (Northern Apennines, Italy), Tectonophysics, 238, 295-315.

Cassano, E., R. Fichera and F. Arisi Rota (1986). Rilievo aeromagnetico d'Italia: alcuni risultati interpretativi, V Convegno Nazionale GNGTS, 19 pp.

Chiappini, M., A. Meloni, E. Boschi, O. Faggioni, N. Beverini, C. Carmisciano and I. Marson (2000). Shaded relief anomaly map of Italy and surrounding marine areas, Annali di Geofisica, 43 (5), 983989.

De Santis, A., M. Chiappini, G. Dominici and A. Meloni (1997). Regional geomagnetic field modeling: the contribution of the Istituto Nazionale di Geofisica, Annali di Geofisica, 40, 1161-1169.

De Santis, A., L. Gaya-Piqué, G. Dominici, A. Meloni, J.M. Torta and R. Tozzi (2003). ITalian Geomagnetic Reference Field (ITGRF): update for 2000 and secular variation model up to 2005 by autoregressive forecasting, Annals of Geophysics, 46 (3), 491-500.

Dominici, G., A. Meloni, M. Miconi, M. Pierozzi and M. Sperti (2007). La Rete Magnetica Italiana e la carta magnetica d'Italia al 2005.0 / Italian Magnetic Network and Geomagnetic Field Maps of Italy at year 2005.0, Bollettino di Geodesia e Scienze Affini, $1,1-47$.

Dominici, G., A. Meloni, M. Sperti, G. Manzo and R. Maseroli (2012). La Rete Magnetica italiana e la Carta Magnetica d'Italia al 2010.0, ISBN 88-523-3559-5.

Encyclopedia of Geomagnetism and Paleomagnetism (2007). Edited by D. Gubbins and E. HerreroBervera. Springer, 1054 pp.

Finlay, C.C., S. Maus, C.D. Beggan, T.N. Bondar, A. Chambodut, T.A. Chernova, A. Chulliat, V.P. Golovkov, B. Hamilton, M. Hamoudi, R. Holme, G. Hulot, W. Kuang, B. Langlais, V. Lesur, F.J. Lowes, H. Luhr, S. Macmillan, M. Mandea, S. McLean, C. Manoj, M. Menvielle, I. Michaelis, N. Olsen, J. Rauberg, M. Rother, T.J. Sabaka, A. Tangborn, L. Toffner-Clausen, E. Thebault, A.W. P. Thomson, I. Wardinski, Z. Wei and T.I. Zvereva (2010). International Geomagnetic Reference Field: the eleventh generation, Geophys. J. Int., 183 (3), 1216-1230; 
doi:10.1111/j.1365-246X.2010.04804.x.

Jolivet, L., C. Facenna, B. Goffè, M. Mattei, F. Rossetti, C. Brunet, F. Storti, R. Funiciello, J.P. Cadet, N. D'Agostino and T. Parra (1998). Midcrustal shear zones in postorogenic extension: example from the northern Tyrrenian Sea, J. Geophys. Res., 103, 12123-12160.

Lanza, R., and A. Meloni (2006). The Earth's magnetism, Springer Verlag, $278 \mathrm{pp}$.

Molina, F., E. Armando, R. Balia., O. Battelli, E. Bozzo, G. Budetta, G. Caneva, M. Ciminale, N. De Florentiis, A. De Santis, G. Dominici, M. Donnaloia, A. Elena, V. Iliceto, R. Lanza, M. Loddo, A. Meloni, E. Pinna, G. Santarato and R. Zambrano (1985). Geomagnetic Survey of Italy. Repeat Stations Network and Magnetic Maps: a Short Report, Annales Geophysicae, 3 (3), 365-368.

Molina, F., E. Armando, R. Balia., O. Battelli, E. Bozzo, G. Budetta, G. Caneva, M. Ciminale, N. De Florentiis, A. De Santis, G. Dominici, M. Donnaloia, A. Elena, V. Iliceto, R. Lanza, M. Loddo, A. Meloni, E. Pinna, G. Santarato and R. Zambiano (1986). Geomagnetic Survey of Italy at 1979.0. Repeat Stations Network and Magnetic Maps, Publ. no. 554, Istituto Nazionale di Geofisica.

Molina, F., E. Armando, R. Balia, O. Battelli, E. Bozzo, G. Budetta, G. Caneva, M. Ciminale, N. De Florentiis, A. De Santis, M. Donnaloia, A. Elena, V. Iliceto, R. Lanza, M. Loddo, A. Meloni, E. Pinna, G. Santarato and R. Zambrano (1994). Geomagnetic Survey of Italy. Repeat station network and magnetic maps. Progetto Finalizzato Geodinamica, Publ. no. 554, Istituto Nazionale di Geofisica.

Morelli, C., M.T. Carrozzo, P. Ceccherini, I. Finetti, C. Gantar, M. Pisani and P. Schmidt di Friedberg (1969). Regional geophysical study of the Adriatic sea, B. Geofis. Teor. Appl., 11 (41/42), 3-56.

Morelli, C. (1970a). Physiography, gravity and magnetism in the Tyrrhenian sea, B. Geofis. Teor. Appl., 12 (48), 275-309.

Morelli, C. (1970b). Bathimetry, gravity and magnetism in the strait of Sicily, Saclantcen Conference, Proc. no. 7, La Spezia.

Servizio Geologico Nazionale (1994). Carta Aeromagnetica d'Italia.

\footnotetext{
${ }^{\star}$ Corresponding author: Guido Dominici, Istituto Nazionale di Geofisica e Vulcanologia, Sezione Roma 2, Rome, Italy; email: guido.dominici@ingv.it. 